\section{From Infancy to Adolescence} Seven Lessons for Creating a Sustainable Graduate Student Orientation Program

Harriet Lightman

Harriet Lightman is Head, Research and
Information Services Department, Northwestern
University Library, Evanston, Illinois.

Correspondence concerning this column should be addressed to Marianne Ryan, Associate University Librarian for Public Services, Northwestern University, 1970 Campus Drive, Evanston, IL 60208; email:marianne-ryan@northwestern.edu.
In recent years, academic librarians have been strengthening the suite of orientation opportunities they offer students and placing a priority on familiarizing them with collections and services to support their academic endeavor. At most universities, the primary-if not the exclusive-target of these efforts is the undergraduate population. Yet graduate students also need a thorough orientation to their postgraduate environment and what the library has to offer. But for a variety of reasons, that audience can be shortchanged. In this column, Harriet Lightman provides an overview of a successful program crafted specifically for doctoral students at a research university. Lightman shares her success story, as well as the lessons learned throughout more than a decade of adapting the program to meet students' changing needs.-Editor

A $\mathrm{t}$ the start of this millennium, emerging formats were shaping a new information landscape, one that heralded a change in library collection development, management, and content as well as instruction, reference service, and outreach. Scholars, too, were beginning to understand the enormous potential of these new formats to transform traditional modes of discourse.

To address these changes and underscore the library's role in this transformation, librarians, faculty, administrators, and information technology professionals from Northwestern University Library (NUL) and the university's Weinberg College of Arts and Sciences (WCAS), in collaboration with the Information Technology (IT) Division, launched an innovative training program aimed at incoming doctoral students in humanities disciplines. ${ }^{1}$ This program, which began in 2002, was preceded by work done in WCAS to assess humanities scholars' knowledge of and skill with emerging technologies and by several other pilot programs. The 2002 event was yet another initiative, this one aimed at engaging incoming humanities doctoral students with faculty, librarians, and IT staff who could explain and demonstrate the role of technology in shaping a new scholarly landscape. Humanities faculty who were already engaged with digital technologies showcased their own projects; librarians and faculty partnered to demonstrate the seriousness and solidity of electronic resources. The day was capped by discussion.

Because the planning and growth of the program are well-documented elsewhere, ${ }^{2}$ the intention of this column is to highlight the lessons learned about event organization and the need for continuous adjustment to each of the major elements, from the smallest detail to the very philosophy behind the training. Now having just finished its twelfth year, the program's longevity speaks to its success. But success did not come easily. A willingness to discard elements that were 
not working or were outmoded, to expand in new directions and contract in others, and to listen to feedback contributed to the event's sustainability.

\section{LESSONS}

\section{Lesson \#1: Start small, think big, and don't be in a hurry.}

The initiatives that preceded the 2002 program helped the planners shape the topics and format of the major event held in September of that year. ${ }^{3}$ Close to fifty humanities doctoral students were invited, along with administrators, technology staff, and faculty. By 2013, the number of invitees to this program, which is now called the Research Resources Forum (RRF), more than tripled and included, in addition to incoming doctoral students in humanities disciplines, some master's degree candidates as well as incoming PhD students from WCAS social sciences disciplines, the School of Education and Social Policy, the School of Communication, and some students from the School of Music. However, few faculty and administrators attended. Additionally, two separate science programs, one for chemistry and one targeted at students in the Interdisciplinary Biological Sciences (IBiS) Program, reached even more students. By 2014, when more than 30 incoming doctoral students in the university's Kellogg School of Management were slated to participate in another segment, this one to include talks from both librarians and Kellogg staff, the program had become an event held on four separate days; it was attended by more than 160 incoming graduate students. Along with the increased numbers came a shift in focus and format. In 2002, a faculty forum served as the equivalent of a keynote panel; this was followed by several break-out sessions, most of which were led by librarians in partnership with faculty. In 2014, the humanities and social sciences portion of the event offered nineteen sessions, all of which were led by librarians and, in one case, a senior member of the IT Division's Academic and Research Technologies (A\&RT) group. Two separate science sessions were offered, and there was one session for the management students. ${ }^{4}$

It took more than a decade to grow the RRF to its current size and scope. Unwavering support from WCAS has been essential to the event's success. Today's program, which is very different from the original concept, was honed over time, shaped by conversation with interested parties around the University and, perhaps most importantly, by patience and a tenacious belief on the part of the organizers and supporters that the value of such an event was profound.

\section{Lesson \#2: Assess the program, using a variety of techniques. Tailor the program to your campus community. Don't be afraid to discard last year's great idea.}

Every year the program has been assessed and adjustments have been made to everything from schedules to lunch menus to session rosters. Even the name of the program changed (see lesson 5). Informal assessment is done through conversations with the planning committee, instructors, students, and campus partners and formally through postevent questionnaires. The content and format of the questionnaires has changed over time. Some questions became irrelevant as the program itself changed, while other questions emerged as important for future planning. The first iterations were distributed both in print and online, although students were inclined to fill out the print version on-site rather than access the online form once the event had ended. In 2012, in an effort to streamline and simplify the evaluation process, paper forms were eliminated, and SurveyMonkey was used to design a new form. In 2014, the survey was significantly simplified yet again as it became clear from low response rates that students were not particularly willing to write lengthy comments.

Adjustment to the session roster is one key to the success and dynamism of the RRF. Determining what to offer is among the trickiest but most rewarding parts of the event. How is that done? Each year the number of students who attend a given session is counted. ${ }^{5}$ These head counts are a very important part of the planning - if a session has fewer than five attendees, it is a candidate for elimination from the event; with fewer than three attendees, it is definitely dropped from the session roster for subsequent years. In addition to the head counts, several other information sources help the planners. Chief among these is information about the mix of incoming students and their specialties. If, for example, there is a large cohort of philosophy graduate students, a session will be tailored to their needs.

Another excellent assessment tool is the post-program debrief. A formal planning committee discussion happens after the student questionnaires are received. Again, some sessions are clearly ready to be dropped, while others emerge as ones to pay attention to in the coming years. From students and instructors alike, in tandem with information received throughout the academic year, planners are aware of new areas of focus; for example, GIS, data literacy, digital humanities, and copyright sessions have been offered in the last few years in response to perceptions of student needs gleaned throughout the academic year. Some topics that were once popular, such as an overview of historical newspapers, are no longer as relevant and are dropped from the roster.

While the survey response rate has never been high, what was learned via the questionnaires and, just as importantly, through conversations with students throughout the academic year was threefold: a full-day program was too long, highly specialized sessions were not meaningful to students who had not yet seen the inside of a Northwestern classroom, and learning about the library's liaison program was extremely important. In 2012, in response to the need to put a face to a subject specialist's name, the "Meet Your Liaison" post-lunch coffee hour was born. The coffee was so well received that it has become a permanent feature of the program. 


\section{MANAGEMENT}

Lesson \#3: Form a planning team whose members have different skills, subject expertise, and familiarity with different university constituencies.

Until recently, much of the program's content was determined by campus partners, and the earliest planning teams consisted of librarians, faculty members, and information technology staff. Now the event is planned mainly by library staff. The original group was led by senior information technology staff from WCAS, and subsequently a librarian became the co-organizer of the event. WCAS provided funding, while administrative support and facilities came from various groups, including the library. A program assistant, event planner, and a student assistant rounded out the team, all of whom were needed to make a success of a full-day event that included three social events—continental breakfast, lunch, and a reception - and talks from faculty and administrators. ${ }^{6} \mathrm{~A}$ few years into the program, several things were clear: the event cost was steadily rising, the planning was too formal and complex for the occasion, student participants were leaving immediately after lunch and not returning for the afternoon events, and the "show-not-tell" sessions were no longer the biggest draw.

In response to the high post-lunch drop-off rate and input from the students themselves, the event was shortened to accommodate complicated student schedules. While the original campus partners-chiefly from WCAS—continued to support the program both financially and intellectually, there was a gradual, general recognition of the need for closer consultation with the librarians who were doing the actual instruction and a need for a thorough grounding in library resources and services. The library had been relying on campus partners to guide the choice of session topics, but some of those topics, while timely at the start of the program, had lost their immediacy for incoming students. To allow for that, and also to take into account the breadth of the program once it expanded beyond the humanities, a planning team was created that included librarians who represented several subject specialties, as well as members of the library's in-house technology support group and representatives from WCAS. Each year, the composition of the planning team is adjusted slightly, to encourage new ideas and insights, and consultation with campus partners continues to help shape the event.

\section{Lesson \#4: Work with campus partners. Promote your program consistently, so it becomes a staple of university-wide orientations and remains responsive to the community it serves.}

Since its inception, this program has been developed and implemented in close cooperation with WCAS and, more recently, in partnership with several other schools around campus. In the early years, when the program was limited to WCAS, funding was straightforward, and attendance was mandatory for the college's incoming doctoral students; accordingly, it was relatively easy to estimate costs and plan for session capacities. When the School of Education and Social Policy, the School of Communication, and the School of Music students were added, getting them on board posed some administrative complexities; also, it was clear that attendance could not be mandated. Funding was in question, as was gathering the names of the students. Working with The Graduate School (TGS), which serves as an umbrella for Northwestern's graduate students, helped the planners to refine the complicated name-gathering process. However, there was a good deal of administrative planning that went into the now smooth-functioning program. The importance of identifying key decision-makers and administrative staff in each department and school and keeping a roster of those contacts cannot be over-stated.

\section{Lesson \#5: Don't be afraid to change the program name, the audience, and the underlying philosophy, but make changes gradually so the "brand" sticks.}

The program is on its fourth name. Now called the Research Resources Forum (RRF), this event began life as the Introduction to Humanities Computing/Electronic Resources Training Day. In 2004, it became the Humanities and Social Science Computing/Introduction to Electronic Resources Training Day. The following year, it was named the Electronic Resources Forum. In 2012, it took on its current name.

At each juncture, the name was changed to reflect the content and purpose of the program. The original name was meant to be workmanlike. The inaugural program was preceded by trial balloons, some of which carried names that, while catchy, were not self-explanatory. The early planning group, seeing what confusion clever names could cause, opted for a plainly descriptive name that reflected the event's objective: to introduce humanities students to new technologies and their power and purpose in humanities scholarship. At the first several events, humanities faculty who were early users of sophisticated technology showcased their projects, including the technical skills and knowledge that were needed, while librarians demonstrated how to use some of the early commercial products that were on the market. While the second title was arguably even more awkward than the first, it too was chosen to be descriptive. It mirrored the fact that while the actual premise and format of the program were not changing, the audience (and subsequently the mix of program instructors and session topics) was being expanded to include the social sciences.

The third title, Electronic Resources Forum, reflected the sea change in the program's purpose. Incoming students clearly had, at minimum, basic technical skills and were conversant, for the most part, in the ways in which format can shape a question. However, they were unfamiliar with the array of sources available to them as Northwestern students. The event had transformed, albeit gradually, into one in which students were introduced to librarians, services, and an array of resources. In 2012, the adoption of the newest 
name signaled that the focus was on research materials and strategies, independent of format.

\section{Lesson \#6: Don't expect instant success. If at first you fail, try again.}

In its earliest years, the event, which is traditionally held the day before the start of fall quarter classes, was small, meaningful, and worked nicely. As it grew, however, the original concept and format became too elaborate for the target audience. Consequently, the event was not hitting the right notes for new graduate students who had not yet set foot in a classroom. Each year, something went awry. There were sessions that were well-prepared, with good-sized preregistrations, but, in the end, no students showed up. One year, the lunch delivery was nearly thirty minutes late, while in other years the end-of-program reception was almost exclusively attended by staff. Instructors cancelled at the last minute, equipment failed, and so on. Yet the mistakes were as instructive as they were aggravating: the reception was eliminated, the afternoon sessions gradually fell by the wayside, and when it became clear that faculty arms needed a great deal of twisting, it was apparent that the era of the teaching partnership was waning. Planners also learned to use session head counts effectively. As the event expanded, the numbers of invited students swelled, planners assumed that everyone who pre-registered would show up, and last-minute registrants were discouraged from attending. Now, aware of the ratio of pre-registrants to no-shows, the planning team responds with an enthusiastic yes to those who, at the last minute, wish to attend.

Many of the more complex elements of the planning process have also been eliminated. In the earliest years, the program was run much like a conference and included individual information packets, name badges in plastic holders, pre-printed schedules, and personal invitations to lunch for faculty and administrators. The time and cost involved, however, were disproportionate to the results.

\section{Lesson \#7: Keep looking to the future.}

The Research Resources Forum is as varied as the interests of the students it serves. In the coming years, Northwestern University librarians look forward to continuing to listen to their constituents and showcasing the wealth of resources and services available to graduate students. The ultimate lesson from this growth and from the consistent support of campus partners is that this program is here to stay.

Partnerships, collaboration, and patience, as well as funding and precise planning, are keys to the success of any library program. The Research Resources Forum planning team and, consequently, the community it serves have benefited from years of trial and error. The planning team is never complacent. Each year brings a new group of students who have unique interests, skills, and research needs. A willingness on the part of the RRF organizers to adapt to a continually changing graduate student community, research environment, and range of information resources and services has meshed with the support of the Northwestern academic community to make the RRF the success it is today.

\section{References}

1. The composition of the planning group for the event described in this column has varied over the years. The original planning team included information technology (IT) professionals, librarians, administrators, and humanities faculty, representing the university's Weinberg College of Arts and Sciences (WCAS), the Information Technology (IT) Division, and the University Library. For a fuller discussion of the early years of this program, see Harriet Lightman and Ruth N. Reingold, "A Collaborative Model for Teaching E-Resources: Northwestern University's Graduate Training Day," portal: Libraries and the Academy 5, no. 1 (January 2005): 23-32, accessed November 16, 2014, http://muse.jhu.edu/journals/portal_libraries _and_the_academy/v005/5.1lightman01.html.

2. Ibid. See also Harriet Lightman and Marianne Ryan, "Innovation in Changing Times: Two New Approaches to User Services" (paper presented at the 77th IFLA World Library and Information Congress, San Juan, PR, August 18, 2011), accessed November 16, 2014, http://conference.ifla.org/past-wlic/2011/197-lightman-en .pdf.

3. Lightman and Reingold, "A Collaborative Model for Teaching E-Resources," 26-27.

4. The Kellogg session included talks by both Kellogg and library staff, while the science sessions included talks by representatives from the IT division.

5. Students preregister for the RRF and for each individual session. While preregistration numbers correspond to the actual number of program attendees, students do not necessarily attend the sessions for which they preregistered.

6. Lightman and Reingold, "A Collaborative Model for Teaching E-Resources," esp. 27. 